\title{
Evaluation of an agro-ecosystem of Campania Plain: The tourist coastal Lakes District of Castelvolturno (Southern Campania, Italy)
}

\author{
M. M. Calandrelli ${ }^{1}$ and R. Calandrelli ${ }^{2}$ \\ ${ }^{1}$ Institute of Agro-environmental and Forest Biology, National Research Council, 111 P. Castellino Street, Naples 80131, \\ ITALY, \\ ${ }^{2}$ Institute for International Legal Studies, National Research Council, 111 P. Castellino Street, Naples 80131, ITALY,
}

\begin{abstract}
The present paper describes the investigation activities on the ground areas of a territory falling within the SIN Domitian Phlegrean and Agro Aversano Coast. It summarizes the general characteristics of the study area and the history of the human activities undertaken over time that may have caused a hazard to the environmental matrices. The results of sampling and analysis activities are shown with the evaluation of non-compliance with law requirements (acceptable limit values of concentration in the soil, subsoil and groundwaters).
\end{abstract}

Keywords: Heavy metals, site of national interest, characterization of a site.

\section{Introduction}

The study area represents a portion of the Campanian Plain area included in the relevant area of Castel Volturno Municipality, near Caserta. This area falls within the perimeter of the area called "Lago Patria and neighbouring lakes" inside the SIN (Site of National Interest) Domitian Phlegrean and Agro Aversano Coast (Law $n^{\circ}$ 426/98). The study area has a morphology determined by the recent tectonic history and by emplacement of alluvial material deposition and evolution of the coastline. The morphology is sub-flat with altitudes that rarely exceed 9 meters above sea level and arrive at $-2,5$ meters above sea level in the retrodunal depressions.

The area is characterized by morphotypes related to the coastal morphology, or to the river dynamics or in some cases to the anthropic origin. The latter are connected to the variety of actions occurring over time. Already in Roman times (sixth and fifth centuries BC), Campania Plain (Southern Italy) has been affected by vast marshes that have made remediation necessary.

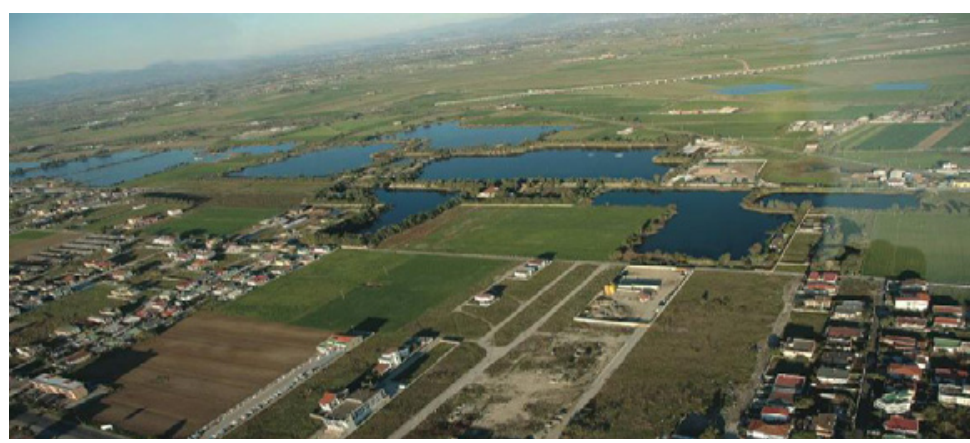

Fig. 1. Study area: the tourist coastal Lakes District of Castelvolturno.

Later on, defense works were carried out to mitigate the hydrogeological risk represented by earth embankments with concrete cladding (Volturno River) or in some cases completely cemented (Regi Lagni). In the test area, the permeability of these lithologies has enabled the development of a significant hydrographic surface network allowing to find a river basin: the basin of Regi
Lagni.

It underlies an area of approximately $1300 \mathrm{sq} \mathrm{km}$ and is characterized by the presence of the channel of Regi Lagni, about $55 \mathrm{~km}$ long, which is the only delivery of stormwater coming from the countryside and the 126 municipalities of the area.

In this context, the excavation of pit quarries for the 
extraction of sand lithotypes being successively abandoned has allowed the formation of numerous ponds, even of considerable size, around which other human activities have developed over time.

\section{Materials and Methods}

The study focused on a portion of territory of about 30 acres occupied by two artificial lakes resulting from the reuse of disused quarries and areas adjacent to them where activities related to livestock farming and agricultural production are carried out. In order to ascertain whether such an use of the land has resulted in a significant change in the natural levels of heavy metals in soil, a study was necessary to assess the need of adopting measures for emergency securing.

The investigation and analysis activities were carried out complying with current regulations, with reference to the specifications of Annex II of the Ministry Decree no. 471/99 "Reference Procedures for collecting and analyzing samples" as well as with APAT directives and ARPA protocols

The study areas were divided according to the type into: land areas and water areas. The investigation campaign consisted in about 35 surveys, 27 for the aquatic areas and 8 for the areas being adjacent to them and soil samples for chemical analysis laboratory were collected from the cores.

The soil samples are representative of the various lithological horizons, one sample every 2 feet depth in the land areas, for a total of 14 levels; four intervals at different depths for the aquatic areas. For each investigation area and for the different environmental compartments, the parameters to be searched were defined according to the type of the site to be examined and to the working activities therein carried out

\section{Results and Discussion}

Some elements were found from laboratory tests whose concentrations exceeded the limit allowed by law (Legislative Decree 152/06).

In the samples taken from sediments of the two lakes being examined only some minor exceedances were detected in the concentrations of As and Sn.

The levels of As in the soils may vary from 1 to 40 $\mathrm{mg} / \mathrm{kg}$ (WHO, 2001), due to agricultural and industrial contamination (use of sewage sludge as well as detergents and / or phosphate-based fertilizers which contain appreciable quantities of this element) (Sturchio et al. 2009).

Even for As a correlation can be assumed between livestock activities that are located on the edge of the area and the prevailing direction of flow directed northward towards the Volturno River, as the sampling points where the highest concentrations of As are found are aligned with it.

In samples of sediment from the points coming from areas close to lakes, exceedances relate mainly to $\mathrm{Sn}$ and
Be. As far as the $\mathrm{Sn}$ is observed, it results a distribution of exceedances being absolutely homogeneous throughout, which could be related to the natural composition of the area soils (Fig. 2).

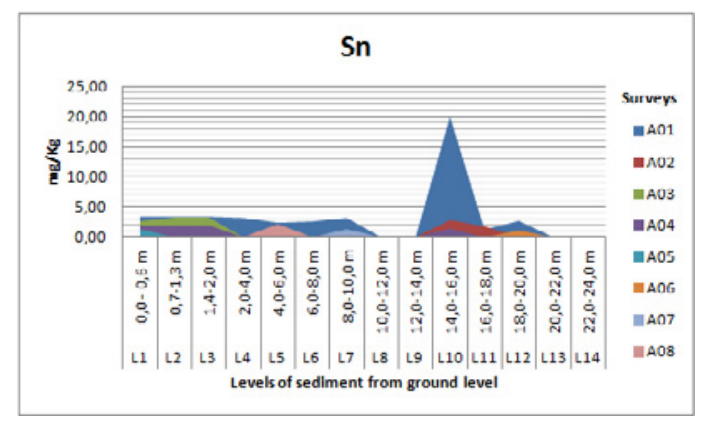

Fig. 2. [Sn] exceeded the limit allowed by law in soil.

The Domitian coast is in fact a reclaimed wetland, characterized by the presence of peat deposits, which may justify the high presence of Sn (Ortolani F. and Aprile F., 1985).

It should be noted also the law limit provided for tin element in areas destined to public and residential green is probably too restrictive, in relation to the low toxicity of this element (Vito M., 2011).

As to exceedances of the limit concentrations reported for Be (Fig. 3), whose widespread distribution in the territory does not allow to establish correlations with a specific pollution source point, it might be thought that in the first instance it may be related to human activities (burning of oil and coal, metal production) for which the $\mathrm{Be}$ is released into the air and, thanks to the rains, it penetrates into the groundwater.

High concentrations of $\mathrm{Be}$ in soil and water can have a negative impact on the environment.

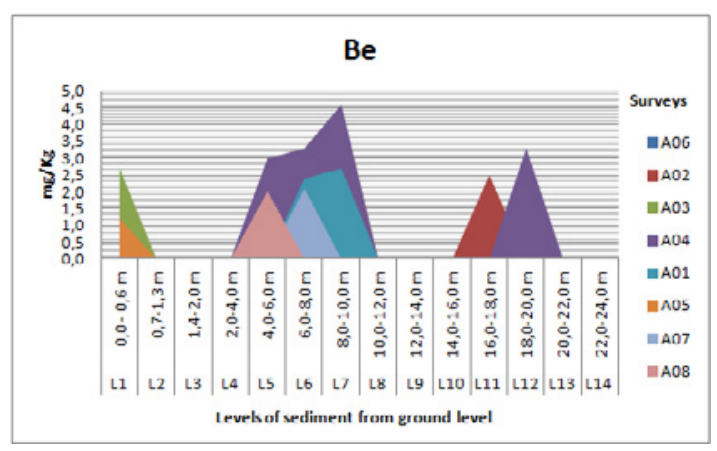

Fig. 3. $[\mathrm{Be}]$ exceeded the limit allowed by law in soil.

The International Agency for Research on Cancer has designated $\mathrm{Be}$ and its compounds as carcinogens. However, exposure to normal levels found in nature is unlikely to have adverse effects on human health.

In just one survey (Fig. 4), in addition to Sn, three other metals such as $\mathrm{Pb}$, total $\mathrm{Cr}$ and $\mathrm{Zn}$ were found at the same depth (14 - 16 meters from g.1.).

The simultaneous presence of three elements in a single point of investigation, being not found in other surveys, indicates that the presence of material whose 
origin could not be natural.

For this reason, the issue should be subjected to a closer examination to test the consistency of the pollutant source and its origin.

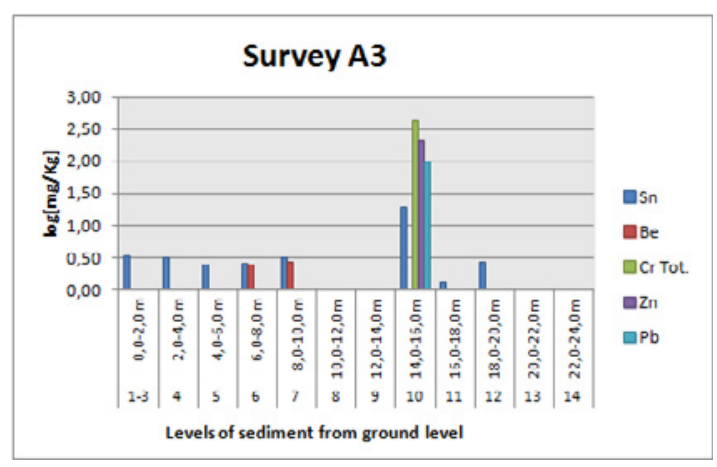

Fig. 4. Heavy metals' concentration exceeded the limit allowed by law in soil.

\section{Conclusion}

The samples collected in the study area does not have significant concentrations of heavy metals ( $\mathrm{Sn}$ and $\mathrm{Be}$ ) seems to be the result of natural geological factors and human activities. However, the peak concentration of some heavy metals ( $\mathrm{Cr}$ tot, $\mathrm{Pb}$ and $\mathrm{Zn}$ ) would require further study.

\section{Acknowledgements}

The authors wish to thank Laura Patricia Arena for her help on English translation.

\section{References}

Ortolani F., Aprile F. Principali caratteristiche stratigrafiche e strutturali dei depositi superficiali della Piana Campana, Boll. Soc. Geol. It., 1985, 104:02, 195-206.

Sturchio E, Minoia C, Zanellato M, Masotti A, Leoni E, Sottani C, Biamonti G, Ronchi A, Casorri L, Signorini S, Imbriani M. ARSENICO, G Ital Med Lav Erg 2009; 31:1, 5-32.

Vito M. I risultati del campionamento dei suoli di Acerra, www.epicentro.iss.it/focus/discariche/vito.asp, 2011.

WHO 2001. Arsenic and arsenic compounds. Environmental Health Criteria 224. World Health Organization, Geneva. 